Supplement of The Cryosphere, 12, 1433-1460, 2018

https://doi.org/10.5194/tc-12-1433-2018-supplement

(C) Author(s) 2018. This work is distributed under

the Creative Commons Attribution 4.0 License.

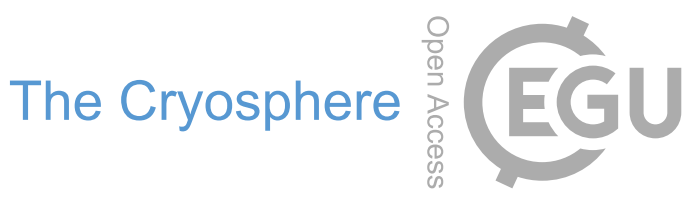

(c) (1)

Supplement of

\title{
Design and results of the ice sheet model initialisation experiments initMIP- Greenland: an ISMIP6 intercomparison
}

\section{Heiko Goelzer et al.}

Correspondence to: Heiko Goelzer (h.goelzer@uu.nl)

The copyright of individual parts of the supplement might differ from the CC BY 4.0 License. 
Table S1 Modelled present-day ice area, ice volume, assumed positive and negative SMB and mass trends in forward experiments for all participating models.

\begin{tabular}{|c|c|c|c|c|c|c|}
\hline Model ID & $\begin{array}{l}\text { Initial ice } \\
\text { area } \\
\left(10^{12} \mathrm{~m}^{2}\right) \\
\end{array}$ & $\begin{array}{l}\text { Initial ice } \\
\text { volume } \\
\left(10^{15} \mathrm{~m}^{3}\right) \\
\end{array}$ & 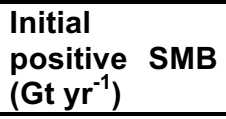 & 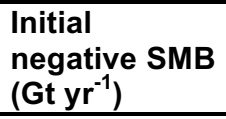 & $\begin{array}{l}\text { Mass change } \\
\text { in ctrl } \\
(\mathrm{mm} \text { SLE) }\end{array}$ & $\begin{array}{l}\text { Mass loss in } \\
\text { asmb-ctrl } \\
\text { (mm SLE) }\end{array}$ \\
\hline ARC-PISM & 1.6998 & 2.9797 & 456.47 & -222.27 & -1 & 141 \\
\hline AWI-ISSM1 & 1.7660 & 2.9822 & 529.01 & -209.26 & 25 & 127 \\
\hline AWI-ISSM2 & 1.7660 & 2.9822 & 529.01 & -209.26 & 25 & 127 \\
\hline BGC-BISICLES1 & 1.7225 & 2.9915 & 448.61 & -103.12 & -14 & 106 \\
\hline BGC-BISICLES2 & 1.7323 & 3.0017 & 450.65 & -103.49 & -8 & 111 \\
\hline BGC-BISICLES3 & 1.7465 & 3.0295 & 452.57 & -102.43 & 1 & 119 \\
\hline DMI-PISM1 & 1.8974 & 3.1881 & 1122.96 & -3.00 & -55 & 205 \\
\hline DMI-PISM2 & 1.9388 & 3.2303 & 1151.06 & -2.24 & -55 & 218 \\
\hline DMI-PISM3 & 1.9708 & 3.2631 & 1175.97 & -1.02 & -52 & 234 \\
\hline DMI-PISM4 & 2.0025 & 3.2942 & 1198.00 & -0.49 & -45 & 249 \\
\hline DMI-PISM5 & 2.0971 & 3.4113 & 1255.71 & 0.00 & -42 & 289 \\
\hline IGE-ELMER1 & 1.7747 & 2.9892 & 556.77 & -192.72 & -3 & 108 \\
\hline IGE-ELMER2 & 1.7664 & 2.9976 & 534.58 & -193.42 & -3 & 108 \\
\hline ILTS-SICOPOLIS & 1.6586 & 2.9168 & 560.46 & -95.97 & -20 & 92 \\
\hline ILTSPIK-SICOPOLIS & 1.8553 & 3.2157 & 531.05 & -428.30 & 2 & 172 \\
\hline IMAU-IMAUICE1 & 1.7393 & 2.9898 & 524.10 & -188.62 & 0 & 134 \\
\hline IMAU-IMAUICE2 & 1.7763 & 3.0572 & 517.88 & -231.18 & 0 & 137 \\
\hline IMAU-IMAUICE3 & 1.7692 & 3.2636 & 517.19 & -205.02 & 0 & 142 \\
\hline JPL-ISSM & 1.7152 & 2.9752 & 530.59 & -163.68 & 2 & 117 \\
\hline LANL-CISM & 1.6610 & 2.9047 & 467.39 & -156.99 & -1 & 115 \\
\hline LSCE-GRISLI & 1.7720 & 2.9976 & 615.05 & -165.27 & 1 & 131 \\
\hline MIROC-ICIES1 & 1.7137 & 2.9369 & 538.80 & -107.75 & -18 & 95 \\
\hline MIROC-ICIES2 & 2.0227 & 2.9622 & 746.75 & -139.28 & -1 & 226 \\
\hline MPIM-PISM & 2.0703 & 3.4362 & 473.16 & -297.88 & -6 & 273 \\
\hline UAF-PISM1 & 1.6866 & 2.9657 & 522.94 & -192.78 & -6 & 93 \\
\hline UAF-PISM2 & 1.7097 & 2.9795 & 519.73 & -330.78 & -9 & 100 \\
\hline UAF-PISM3 & 1.6940 & 2.9823 & 518.44 & -214.11 & 19 & 104 \\
\hline UAF-PISM4 & 1.8837 & 2.8907 & 519.83 & -1597.41 & -80 & 98 \\
\hline UAF-PISM5 & 1.9125 & 2.9075 & 516.76 & -1799.81 & -97 & 99 \\
\hline UAF-PISM6 & 1.8917 & 2.9102 & 515.16 & -1774.30 & -84 & 106 \\
\hline UCIJPL-ISSM & 1.7469 & 2.9878 & 570.22 & -85.88 & -7 & 87 \\
\hline ULB-FETISH1 & 1.6596 & 2.9631 & 508.40 & -164.82 & 0 & 74 \\
\hline ULB-FETISH2 & 1.6812 & 2.9443 & 504.11 & -201.30 & 91 & 116 \\
\hline VUB-GISM1 & 1.9436 & 3.1465 & 606.43 & -322.94 & -12 & 167 \\
\hline VUB-GISM2 & 1.9398 & 3.1467 & 601.84 & -329.43 & -13 & 166 \\
\hline
\end{tabular}



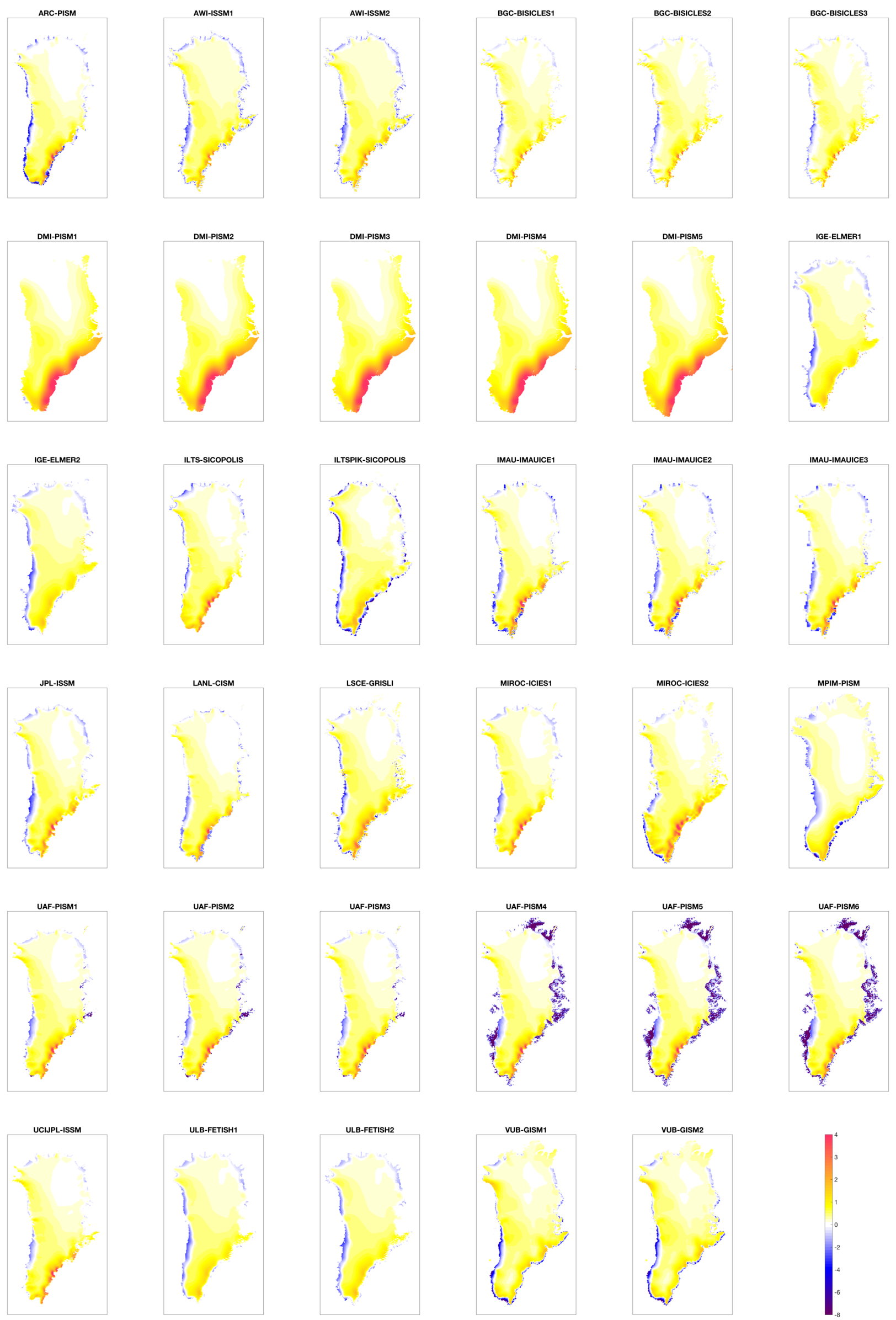

Figure S1: Initial surface mass balance forcing. The data are masked to the ice mask of each individual model. 

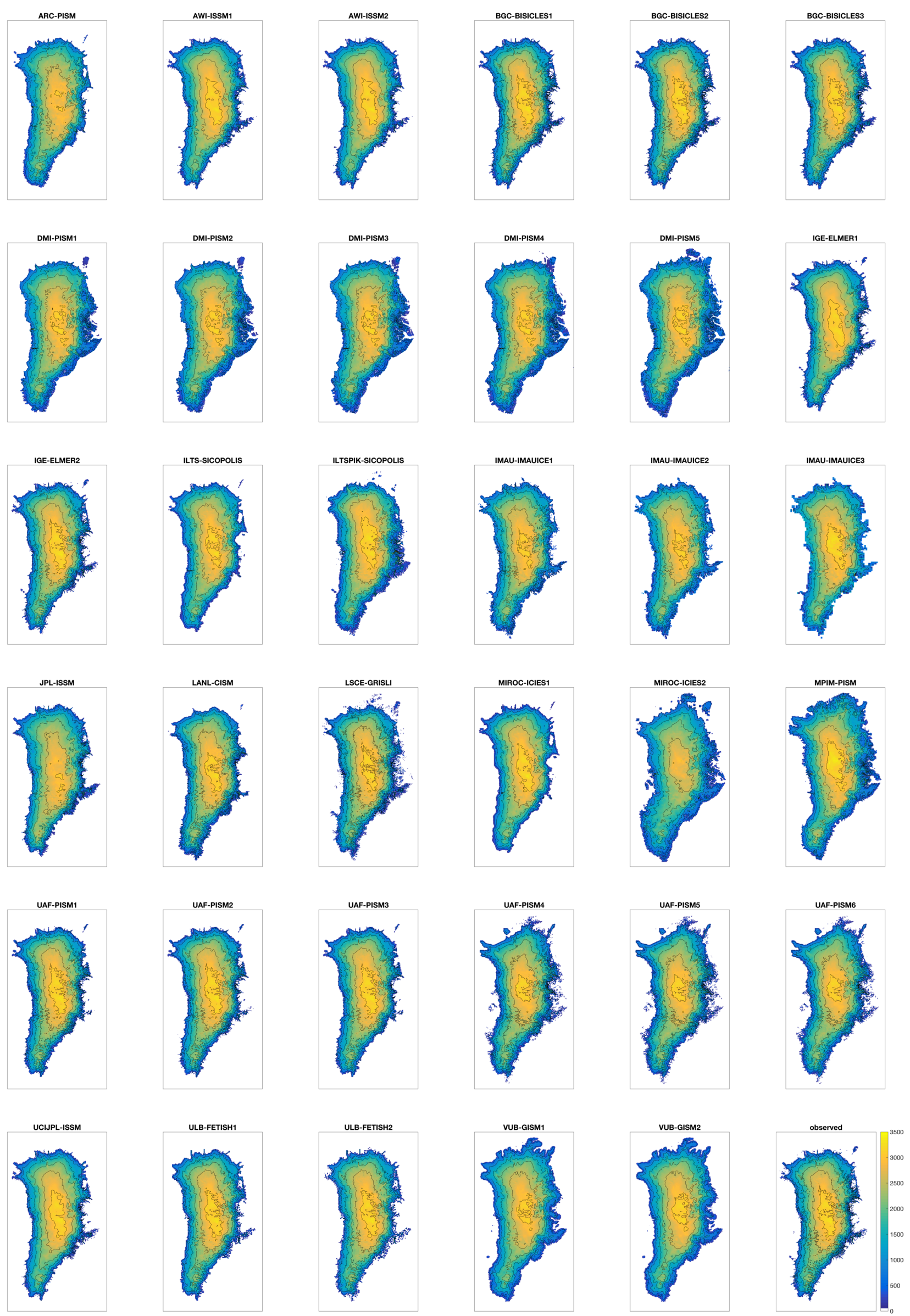

Figure S2: Ice thickness at the end of experiment init. The data are masked to the ice mask of each individual model. Observations in the lower right are from Morlighem et al. (2014) 

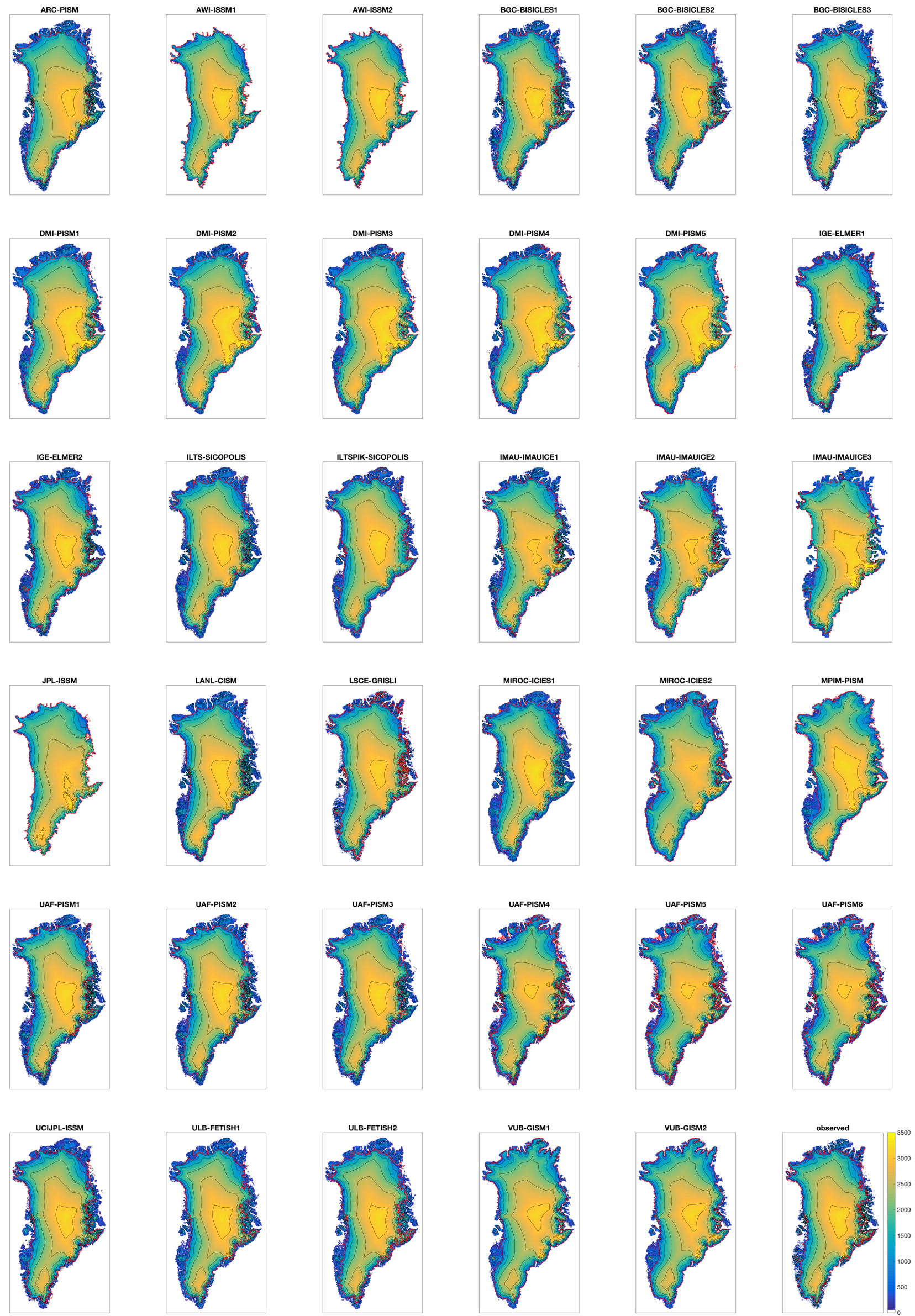

Figure S3: Initial surface elevation and ice sheet mask (red contours). The data are masked to the continent mask of each individual model except for AWI and JPL, where surface elevation is not defined outside of the ice sheet mask. Observations in the lower right are from Morlighem et al. (2014). 

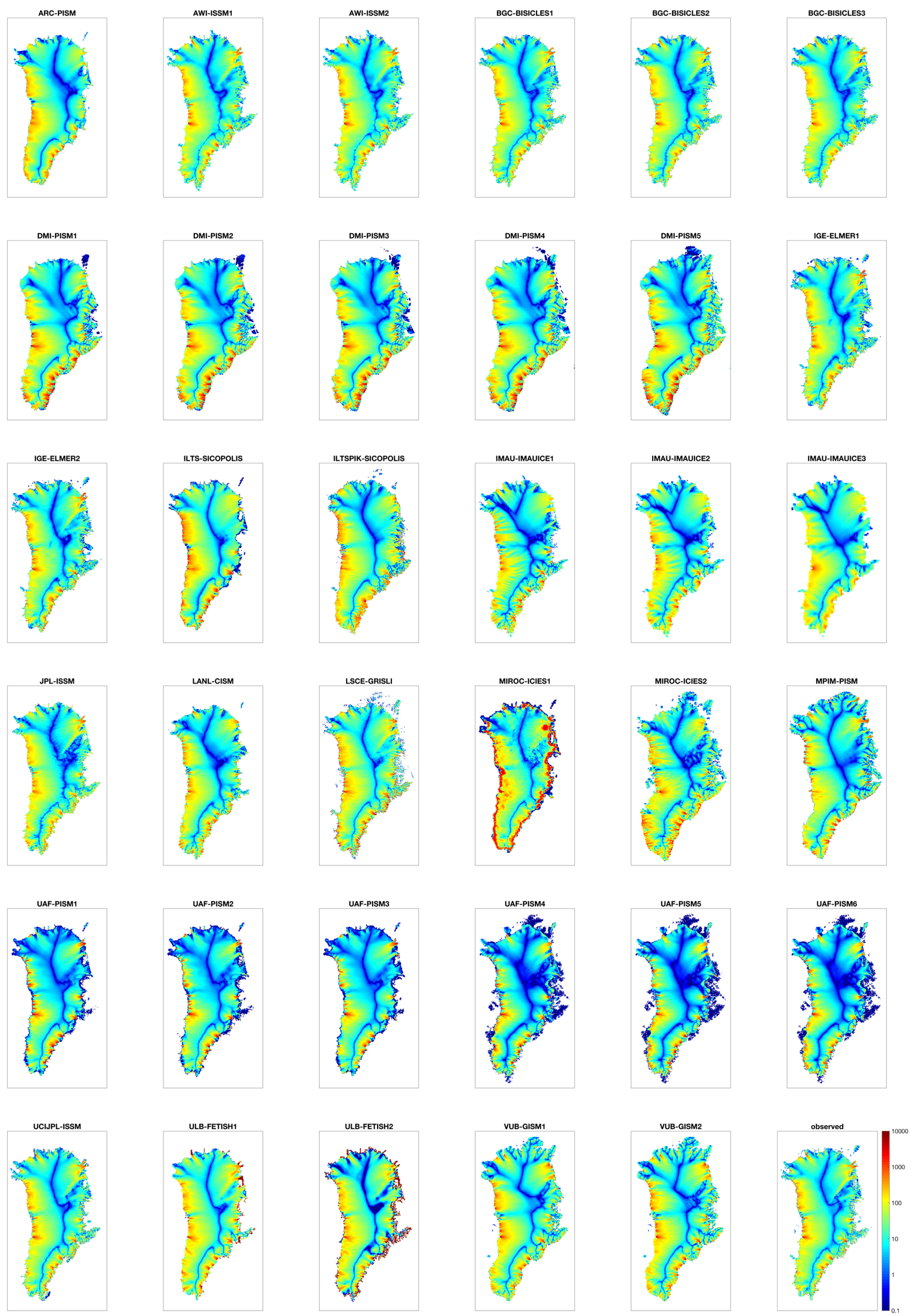

Figure S4: Initial vertically averaged horizontal velocity magnitude. The data are masked to the ice mask of each individual model. Observations in the lower right are from Joughin et al. (2016). 

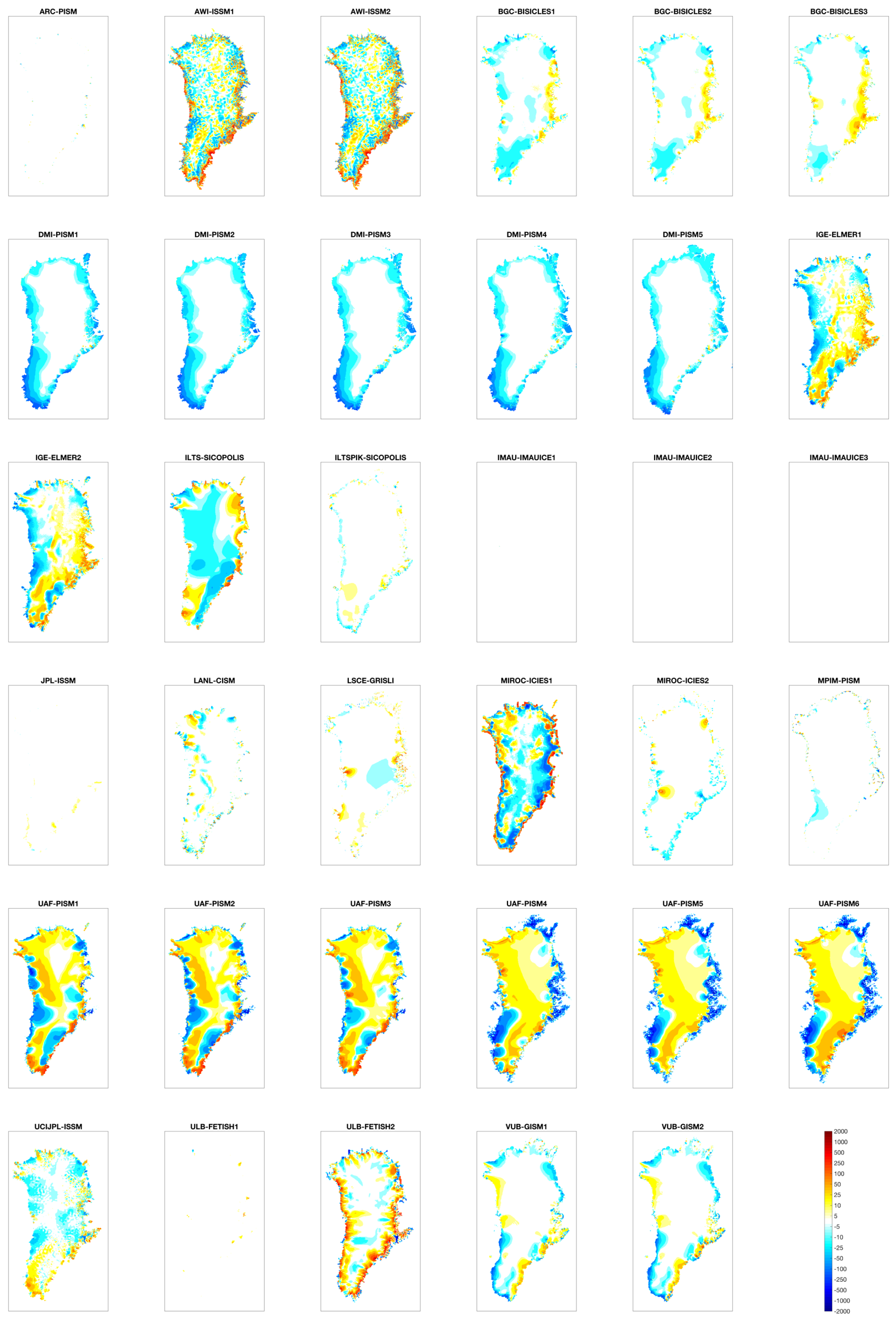

Figure S5: Ice thickness change in experiment $c t r l$ after 100 years. Note the nonlinear contour intervals. 

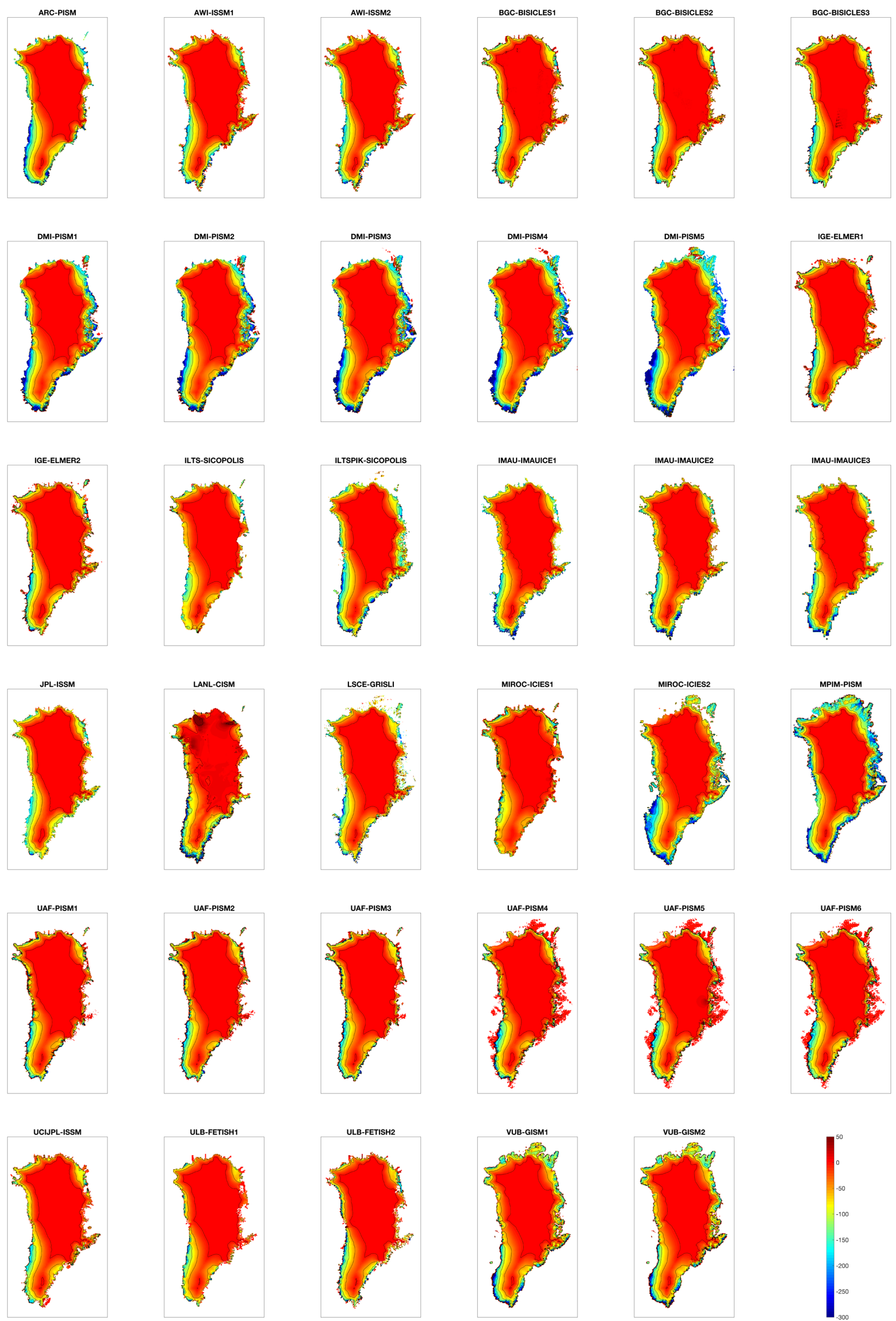

Figure S6: Difference in ice thickness change $(a s m b-c t r l)$ after 100 years. 

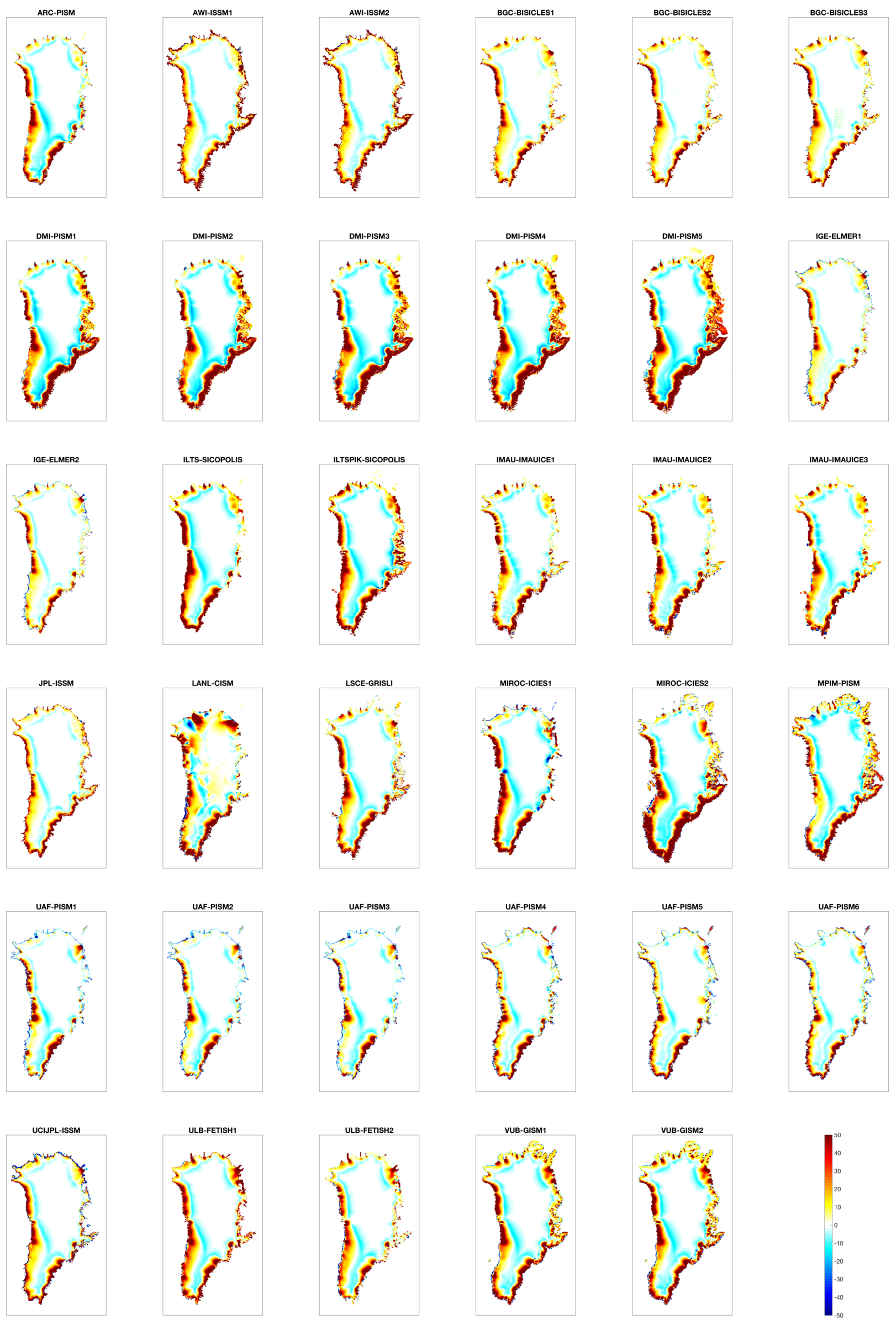

Figure S7: Dynamic ice thickness change after 100 years. This diagnostic is calculated as the residual between the time-integrated SMB anomaly and the difference in modelled ice thickness change (asmb - ctrl). Positive values indicate dynamic thickening, where less ice is lost compared to what the time-integrated SMB anomaly alone would predict. 